\title{
Standardized Postnatal Management of Infants with Congenital Diaphragmatic Hernia in Europe: The CDH EURO Consortium Consensus - 2015 Update
}

\author{
Kitty G. Snoek ${ }^{a} \quad$ Irwin K.M. Reiss ${ }^{a}$ Anne Greenough ${ }^{c}$ Irma Capolupo ${ }^{\mathrm{e}}$ \\ Berndt Urlesberger $^{f} \quad$ Lucas Wessel $^{g}$ Laurent Storme ${ }^{\text {h }}$ Jan Deprest ${ }^{d, i}$ \\ Thomas Schaible ${ }^{g}$ Arno van Heijst ${ }^{b}$ Dick Tibboel ${ }^{a}$ for the CDH EURO Consortium \\ ${ }^{a}$ Erasmus MC - Sophia Children's Hospital, University Medical Center Rotterdam, Rotterdam, and ${ }^{b}$ Radboud University \\ Medical Centre, Nijmegen, The Netherlands; ' King's College and ${ }^{\mathrm{d}}$ University College London Hospitals, London, UK; \\ e Bambino Gesu Children's Hospital, Rome, Italy; ${ }^{\mathrm{f}}$ Medical University Graz, Graz, Austria; ${ }^{9}$ Universitätsklinikum Mannheim, \\ Mannheim, Germany; ${ }^{\text {h} H o ̂ p i t a l ~ J e a n n e ~ d e ~ F l a n d r e, ~ L i l l e, ~ F r a n c e ; ~ ' U n i v e r s i t y ~ H o s p i t a l ~ K U ~ L e u v e n, ~ L e u v e n, ~ B e l g i u m ~}$
}

\author{
Key Words \\ Congenital diaphragmatic hernia - Standardized treatment · \\ Consensus
}

\begin{abstract}
In 2010, the congenital diaphragmatic hernia (CDH) EURO Consortium published a standardized neonatal treatment protocol. Five years later, the number of participating centers has been raised from 13 to 22. In this article the relevant literature is updated, and consensus has been reached between the members of the CDH EURO Consortium. Key updated recommendations are: (1) planned delivery after a gestational age of 39 weeks in a high-volume tertiary center; (2) neuromuscular blocking agents to be avoided during initial treatment in the delivery room; (3) adapt treatment to reach a preductal saturation of between 80 and $95 \%$ and postductal saturation $>70 \%$; (4) target $\mathrm{PaCO}_{2}$ to be between 50 and $70 \mathrm{~mm} \mathrm{Hg}$; (5) conventional mechanical ventilation to be the optimal initial ventilation strategy, and (6) intrave-
\end{abstract}

The Members of the CDH EURO Consortium Group are listed in the Appendix.

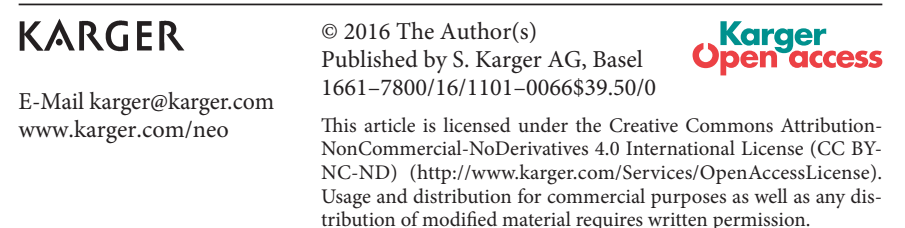

nous sildenafil to be considered in $\mathrm{CDH}$ patients with severe pulmonary hypertension. This article represents the current opinion of all consortium members in Europe for the optimal neonatal treatment of $\mathrm{CDH}$.

(c) 2016 The Author(s)

Published by S. Karger AG, Basel

\section{Introduction}

In 2008, the congenital diaphragmatic hernia (CDH) EURO Consortium was set up and during a consensus meeting drafted a standardized neonatal treatment protocol to improve outcome and permit comparison of outcome data [1]. Since then the number of participating centers has increased from 13 to 22 specialized $\mathrm{CDH}$ centers from all over Europe, and the guidelines from 2010 have been widely cited. Moreover, after the implementation of the protocol, the survival rate has increased from 67 to $88 \%$ in 2 centers. This indicates the impact of the original standardized protocol. After 5 years of additional research including a multicenter randomized clinical trial on initial ventilation strategy (VICI-trial; Netherlands Trial Register, NTR 1310), we aimed to update the standardized neonatal treatment protocol for 
$\mathrm{CDH}$. All recommendations were summarized and compared with the protocol in 2010 (online suppl. file; see www.karger.com/doi/10.1159/000444210 for all online suppl. material).

\section{Methods}

The studies were graded according to the Scottish Intercollegiate Guidelines Network (SIGN) criteria [2]. Five experts individually primarily determined the levels of evidence on the guidance of the SIGN checklist. Differences in opinion were primarily discussed between the five experts until full consensus was reached, and thereafter consensus was reached between all participating centers. The final consensus statement, therefore, represents the opinion of all participating centers based on the interpretation of the recent literature from 2010 to 2015 and includes the main findings of the so-called VICI-trial [3]. A consensus meeting, in which neonatologists, pediatric intensivists, gynecologists, prenatal physicians, pediatric surgeons, pediatric cardiologists and general pediatricians from 22 centers participated, was organized to discuss the most controversial recommendations. If it was very hard to reach consensus on a specific issue, the consortium concurred to investigate those issues in future randomized trials. The levels of evidence and grades of recommendation according to the SIGN criteria are presented in online supplementary tables 1 and 2, respectively.

\section{Results}

\section{Prenatal Management}

With the increased use of second trimester 2D ultrasound and/or MRI, CDH has become a prenatal diagnosis. Subsequently, a more detailed expert evaluation should be performed to determine the location of the defect, the observed/expected lung-to-head ratio $(\mathrm{O} / \mathrm{E}$ LHR) and the position of the liver (intra-abdominal or intrathoracic), in addition to ruling out additional congenital anomalies or syndromes $[4,5]$. Associated congenital anomalies, such as chromosomal or genitourinary anomalies, are present in about 25\% [6] and cardiac anomalies in about $20 \%$ of cases [7]. Comprehensive assessment will also include invasive sampling for high-resolution genetic testing. Only once a comprehensive assessment has been made can multidisciplinary prenatal counseling by clinicians in tertiary centers be offered to inform parents about the estimated prognosis after birth. Several other additional imaging methods, such as lung volumetry, 3D ultrasound and Doppler studies of the pulmonary vascularization, have been shown in individual series to be prognostic for pulmonary hypertension, the need for extracorporeal membrane oxygenation (ECMO) and survival [8]. All of these remain research tools, how- ever, but may ultimately improve the predictive value of prenatal testing.

An experienced tertiary center with a high case volume ( $\geq 6 \mathrm{CDH}$ patients per year) is the optimal environment for the delivery and neonatal treatment of prenatally diagnosed CDH fetuses $[9,10]$. Prenatal intervention by fetal endoscopic tracheal occlusion (FETO) has been proposed to promote lung growth [11]. Therefore, FETO is being evaluated in two randomized clinical trials both in moderate (first interim analysis stage reached; $>100$ patients randomized) and severe cases ( $>25$ patients randomized) in centers in Europe, Australia and Canada (TOTAL trial [12]; NCT01240057). Current reported survival rates are on average around $50 \%$, yet there is a significant impact of gestational age at delivery. In the largest cohort study where $17.1 \%$ of all patients were born under 32 weeks, the survival rate was $49.4 \%$ for isolated left $\mathrm{CDH}$ and $37.9 \%$ for isolated right $\mathrm{CDH}$ [13]. This suggests that FETO introduces a significant risk for prematurity and all its consequences. It is recommended therefore that - while waiting for the results - FETO should not be performed outside the trial [11]. According to the consensus statement of the National Institutes of Health (NIH), CDH fetuses at risk for delivery before 34 weeks of gestation should be given prenatal steroid therapy.

\section{Delivery}

The timing and preferred mode of delivery in $\mathrm{CDH}$ pregnancies are still controversial. Hutcheon et al. [14] showed that neonatal and infant mortality significantly decreased with advancing gestation, from 25 and $36 \%$ at 37 weeks of gestation, respectively, to 17 and $20 \%$ at 40 weeks of gestation, respectively. Moreover, a study from Odibo et al. [15] among $107 \mathrm{CDH}$ cases found that gestational age at delivery was inversely correlated to the need for ECMO. However, Safavi et al. [16] found no difference in mortality when dividing gestational age at delivery categorically as under 37 weeks, $37-38$ weeks and 39 weeks or beyond. Neither did they find a difference in mortality between vaginal and cesarean delivery [16]. In the absence of true convincing data it seems intuitive to schedule delivery (induced delivery or cesarean section) carefully in the best possible conditions also dependent of maternal indications, i.e. at 39 weeks or beyond and in the presence of the relevant clinicians.

\section{Recommendations (Prenatal Management and Delivery)}

- Following prenatal diagnosis, disease severity should be assessed at an experienced center. This will involve 
measurement of the O/E LHR and position of the liver ( grade of recommendation $=\mathrm{D})$.

- In case of an anticipated birth prior to 34 weeks of gestation, antenatal steroids should be given (grade of recommendation $=\mathrm{D}$ ).

- Delivery after a gestational age of 39 weeks in a highvolume tertiary center should be planned (grade of recommendation $=\mathrm{D}$ ).

\section{Delivery Room Management and Treatment in the Initial Postnatal Phase}

Initial treatment and procedures in the delivery room are based on the updated Guidelines of the International Consensus on Cardiopulmonary Resuscitation and Emergency Cardiovascular Care Science with Treatment Recommendations [17].

\section{Monitoring and Goal of Treatment}

Measurements of heart rate, pre- and postductal saturations and intra-arterial blood pressure are recommended. The key principles are the avoidance of high airway pressures and the establishment of adequate perfusion and oxygenation (based on preductal arterial saturation, $\mathrm{SpO}_{2}$ measurements). In a study from Dawson et al. [18] in term and preterm healthy neonates, the overall $\mathrm{SpO}_{2}$ values at 10 min after birth were median $94 \%$ (interquartile range $91-97 \%$ ) in preterm infants and median $97 \%$ in term infants (interquartile range $92-98 \%$ ). Based on expert opinion, the consortium agreed on preductal $\mathrm{SpO}_{2}$ boundaries in the delivery room of $80-95 \%$. In the first $2 \mathrm{~h}$ after birth, preductal $\mathrm{SpO}_{2}$ levels as low as $70 \%$ are acceptable if they are improving without ventilator changes, if organ perfusion is satisfactory, as indicated by a $\mathrm{pH}$ $>7.2$, and if ventilation is adequate $\left(\mathrm{PaCO}_{2}<65 \mathrm{~mm} \mathrm{Hg}\right.$, $8.6 \mathrm{kPa})$. Since there is growing evidence that room air is less harmful than 1.0 fractional inspired oxygen $\left(\mathrm{FiO}_{2}\right)$ in the resuscitation of term infants $[19,20]$, it may be better for $\mathrm{CDH}$ infants to start with $\mathrm{FiO}_{2}$ lower than 1.0. The aim for preductal saturation is $80-95 \%$ after the first hour of life. Thus, to avoid hyperoxia, supplemental oxygen should be diminished by reducing the oxygen fraction when preductal saturation exceeds $95 \%$.

\section{Intubation and Ventilation}

The consortium recommends intubating infants with prenatally diagnosed $\mathrm{CDH}$ immediately after birth as a standard of care. The position of the endotracheal tube should be confirmed by end-tidal $\mathrm{CO}_{2}$ monitoring. However, based on expert opinion, in those infants who are predicted to have good lung development based on their pre- natal assessment (e.g. left-sided defect, O/E LHR $>50 \%$, and liver down), spontaneous breathing could be considered instead to prevent ventilator-induced lung injury. Low peak pressures, preferably $<25 \mathrm{~cm} \mathrm{H}_{2} \mathrm{O}$, are recommended to avoid lung damage to the ipsilateral and contralateral lung.

Sedation and Analgesia/Paralysis for Intubation

Carbajal et al. [21] have studied physiological responses of neonates to awake intubation, and they reported significant rises in systemic arterial blood pressure and intracranial pressure, as well as significant decreases in heart rate and transcutaneous oxygen saturations. In 166 infants Caldwell and Watterberg [22] found that premedication for intubation significantly attenuated both the clinical pain score and the increase in blood glucose as markers of acute stress. Moreover, it seems that intubation success rates progressively improve with premedication, although in some cases this is not possible due to a lack of vascular access [23]. Murthy et al. [24] have shown no beneficial effects of administration of neuromuscular blocking agents immediately after intubation; in fact lung compliance deteriorated upon administration.

\section{Naso- or Orogastric Tube}

The consortium recommends immediate placing of an oro- or nasogastric tube with continuous or intermittent suctioning in order to prevent bowel distension and any additional ipsilateral lung compression.

\section{Vascular Access}

As preductal $\mathrm{PaO}_{2}$ measurements reflect the level of delivered oxygen to the brain, the arterial line should preferably be inserted into the right radial artery - also for blood sampling and monitoring of the arterial blood pressure. Alternatively, an umbilical arterial line may be placed. This is less desirable, however, than a right radial artery line because it reflects the postductal situation, but on the other hand, it may give more secure longer-term arterial access. Each procedure should be performed as soon as possible. It is important, however, to prevent further agitation from recurrent insertion attempts as this may impair postnatal adaptation [25].

\section{Blood Pressure Control}

Measures to increase the systemic blood pressure may minimize the right-to-left shunting. However, there is no need to increase blood pressure levels to supranormal values if the preductal saturation remains above $80 \%$. Therefore, the consortium recommends maintaining arterial blood pressure at normal levels for gestational age if pre- 
ductal saturations remain between 80 and $95 \%$. In the case of hypotension and/or poor tissue perfusion, a fluid bolus of $10-20 \mathrm{ml} / \mathrm{kg} \mathrm{NaCl} 0.9 \%$ should be administered, although no more than 2 times. If tissue perfusion and blood pressure do not improve, inotropic and/or vasopressor medication should be considered according to local practice. Hydrocortisone may be used in the early phase for the treatment of hypotension after other treatment has failed [26].

\section{Surfactant}

There is no rationale for surfactant therapy because in $\mathrm{CDH}$ patients surfactant amounts are likely to be appropriate to lung size [27].

Recommendations

- After delivery, the infant should be intubated routinely without bag and mask ventilation (grade of recommendation $=\mathrm{D}$ ).

- The goal of treatment in the delivery room is achieving acceptable preductal saturation targets, i.e. between 80 and $95 \%$ (grade of recommendation = D).

- Ventilation in the delivery room should be done with a peak pressure as low as possible, preferably with 25 $\mathrm{cm} \mathrm{H}_{2} \mathrm{O}$, or below that (grade of recommendation $=$ D).

- An oro- or nasogastric tube with continuous or intermittent suction should be placed (grade of recommendation $=\mathrm{D})$.

- Arterial blood pressure has to be maintained at a normal level for gestation. In the case of hypotension and/ or poor tissue perfusion, $10-20 \mathrm{ml} / \mathrm{kg} \mathrm{NaCl} 0.9 \%$ should be administered 2 times (grade of recommendation $=\mathrm{D})$.

- In cases of persistent hypotension after the administration of $\mathrm{NaCl} 0.9 \%$, inotropic and vasopressor agents should be considered (grade of recommendation $=\mathrm{D}$ ).

- In CDH infants who are predicted to have good lung development based on their prenatal assessment (e.g. left-sided defect, O/E LHR $>50 \%$, and liver down), spontaneous breathing could be considered (grade of recommendation $=\mathrm{D}$ ).

- Premedication should be given before intubation if possible (grade of recommendation $=\mathrm{D}$ ).

- Neuromuscular blocking agents should be avoided during initial treatment in the delivery room (grade of recommendation $=\mathrm{D}$ ).

- No routine use of surfactant in either term or preterm infants with $\mathrm{CDH}$ (grade of recommendation = D).
Ventilation Management in the Intensive Care Unit

Permissive hypercapnia and 'gentle ventilation' have been reported to increase survival in neonates with $\mathrm{CDH}$ $[28,29]$. A ventilation strategy aiming for preductal saturation between 80 and $95 \%$, postductal saturation above $70 \%$ and arterial $\mathrm{CO}_{2}$ levels between 50 and $70 \mathrm{~mm} \mathrm{Hg}$ (6.9-9.3 $\mathrm{kPa}$, permissive hypercapnia) is well accepted. In the first $2 \mathrm{~h}$ after birth, preductal $\mathrm{SpO}_{2}$ levels as low as $70 \%$ are acceptable provided they are slowly improving and organ perfusion is satisfactory (indicated by a $\mathrm{pH}>7.2$ ), and if ventilation is adequate $\left(\mathrm{PaCO}_{2}<65 \mathrm{~mm} \mathrm{Hg}, 8.6\right.$ $\mathrm{kPa})$. Thereafter, preductal saturation levels are preferably kept between 85 and 95\%. In individual cases, however, levels down to $80 \%$ may be accepted, providing organs are well perfused, as indicated by a $\mathrm{pH}>7.2$, lactate levels $<5 \mathrm{mmol} / \mathrm{l}$ and urinary output $>1 \mathrm{ml} / \mathrm{kg} / \mathrm{h}$. Postductal saturations should remain above $70 \%$. Oxygen toxicity can be avoided by decreasing $\mathrm{FiO}_{2}$ on the guidance of the saturation levels described above. The optimal initial ventilation strategy was investigated in a collaborative initiative from the $\mathrm{CDH}$ EURO Consortium (VICI-trial, NTR 1310) [30]. Although the primary outcome (death/bronchopulmonary dysplasia at day 28) was not significantly different between the two groups, it was found that infants initially ventilated by conventional mechanical ventilation required a significantly shorter duration of ventilation, had less need for inhaled nitric oxide (iNO) or sildenafil, had a shorter duration of vasoactive medication and were less likely to require ECMO [3]. Therefore, the CDH EURO Consortium recommends conventional mechanical ventilation as the initial ventilation strategy. Recommendations for initial ventilation settings for pressure-controlled ventilation are summarized below. In the case of weaning, the peak pressure should primarily be reduced. Thereafter, frequency or $\mathrm{PIP} / \mathrm{PEEP}$ may be reduced as long as $\mathrm{pCO}_{2}<50 \mathrm{mmHg}$ $(6.7 \mathrm{kPa})$. In general, the consortium recommends aiming for a limitation of peak pressure to $25 \mathrm{~cm} \mathrm{H}_{2} \mathrm{O}$ or less, a PEEP of $3-5 \mathrm{~cm} \mathrm{H}_{2} \mathrm{O}$ and adjustment of the ventilator rate to obtain $\mathrm{PaCO}_{2}$ between 50 and $70 \mathrm{~mm} \mathrm{Hg}$ (6.9-9.3 $\mathrm{kPa}$ ). If a PIP of $>28 \mathrm{~cm} \mathrm{H}_{2} \mathrm{O}$ is necessary to achieve $\mathrm{pCO}_{2}$ and saturation levels within the target range, other treatment modalities (such as high-frequency oscillatory ventilation or ECMO) should be considered.

\section{Chest Radiograph}

To assess the patient's initial condition, a chest radiograph should be obtained as soon as possible. 
Recommendations

- Conventional mechanical ventilation is the optimal initial ventilation strategy (grade of recommendation $=\mathrm{C}$ ).

- High-frequency oscillatory ventilation can be used as rescue therapy if conventional mechanical ventilation fails (grade of recommendation $=\mathrm{D}$ ).

- Adapt ventilation settings to reach a preductal saturation between 80 and $95 \%$ and a postductal saturation above $70 \%$ (grade of recommendation = D).

- The target $\mathrm{PaCO}_{2}$ should be between 50 and $70 \mathrm{~mm}$ $\mathrm{Hg}(6.9-9.3 \mathrm{kPa}$; grade of recommendation = D).

- Pressure-controlled ventilation: initial settings are a PIP $<25 \mathrm{~cm} \mathrm{H}_{2} \mathrm{O}$ and a PEEP of 3-5 $\mathrm{cm} \mathrm{H}_{2} \mathrm{O}$; ventilator rate of $40-60 / \mathrm{min}$ (grade of recommendation $=\mathrm{D}$ ).

- After stabilization, reduce $\mathrm{FiO}_{2}$ if the preductal saturation is above $95 \%$ (grade of recommendation $=\mathrm{D}$ ).

\section{Further Management in the Intensive Care Unit}

Sedation and Analgesia

A wide range of sedative and analgesic practices has been described [31, 32]. Most centers use opioids such as morphine sulfate or fentanyl. Although there is no specific evidence in infants with $\mathrm{CDH}$, neuromuscular blockade is associated with side effects such as hypoxemia and thus should be avoided. Infants should remain sedated during mechanical ventilation until weaning form mechanical ventilation is commenced.

\section{Monitoring}

Heart rate, invasive blood pressure, $\mathrm{pO}_{2}$ and $\mathrm{pCO}_{2}$, and pre- and postductal saturation should be monitored routinely. A head ultrasound scan should be performed at a time when there is little danger of arousing the newborn. Monitoring the regional cerebral oxygenation saturation with near infrared spectroscopy and transcutaneous saturation measurements may be indicated [33], although its additional value in $\mathrm{CDH}$ infants is not yet clear. Sedation and analgesia should be started as soon as venous access is established. Careful monitoring of the blood pressure is then warranted because more fluid volumes or vasoactive drugs may be needed in view of the potential adverse hemodynamic effect of sedatives, in particular midazolam. Supportive care such as cocooning and swaddling is recommended to prevent stress from too much noise, light and nociceptive stimulation. The infant's condition should be regularly assessed using validated analgesia and sedation scoring systems, such as the COMFORT behavior score [34].
Hemodynamic Management

Hemodynamic management should be aimed at achieving appropriate end-organ perfusion determined by heart rate, urine output and lactate levels. If the heart rate is within the normal range [35], urine output is over $1.0 \mathrm{ml} / \mathrm{kg} / \mathrm{h}$, lactate concentration is $<3 \mathrm{mmol} / \mathrm{l}$ and there are no other symptoms of poor tissue perfusion, inotropic or vasopressor support is not required. Echocardiography is indicated if there are signs of poor perfusion or if the blood pressure is below the normal level for gestation with a preductal saturation below $80 \%$. This may show whether the poor perfusion is due to hypovolemia or myocardial dysfunction. If there is hypovolemia, saline fluid therapy should be given $(10-20 \mathrm{ml} / \mathrm{kg} \mathrm{NaCl} 0.9 \%$ or Ringer lactate up to 2 times during the first $2 \mathrm{~h}$ ) [36]. If necessary, this should be followed by inotropic and/or vasopressor therapy. Hydrocortisone may be used for the treatment of hypotension after other treatment has failed.

\section{Recommendations}

- Infants should be sedated and be monitored using validated analgesia and sedation scoring systems (grade of recommendation $=\mathrm{D}$ ).

- Neuromuscular blocking agents should be avoided if possible (grade of recommendation $=\mathrm{D}$ ).

- If symptoms of poor perfusion and/or blood pressure below the normal level for gestation occur and are associated with preductal saturation below $80 \%$, echocardiographic assessment should be performed (grade of recommendation $=\mathrm{D}$ ).

- In case of hypovolemia, fluid therapy (10-20 ml/kg $\mathrm{NaCl} 0.9 \%$ or Ringer lactate) up to 2 times during the first two hours may be given and followed if necessary by administration of inotropic and/or vasopressor agents (grade of recommendation $=\mathrm{D}$ ).

\section{Pulmonary Hypertension}

A 2D echocardiography performed within the first $24 \mathrm{~h}$ after birth remains the best modality to (1) rule out the presence of cardiac anomalies; (2) assess the right heart function, and (3) determine the amount of pulmonary hypertension classified accordingly (less or more than $2 / 3$ systemic blood pressure) $[37,38]$. Especially in severe cases of pulmonary hypertension, a cardiac ultrasound may help to evaluate right ventricular dysfunction and/or right ventricular overload, which condition can also lead to left ventricular dysfunction [39].

There is no evidence for the usefulness of increasing systemic vascular resistance to treat right-to-left shunting, but a number of centers from the consortium suggest us- 
ing inotropic or vasopressor agents such as dopamine, dobutamine and (nor)epinephrine to maintain blood pressure at normal levels for gestation [40]. If preductal saturation falls below $85 \%$ and/or if there are signs of poor organ perfusion, treatment of pulmonary hypertension should be initiated. The first choice would be iNO, which is a pulmonary vasodilator. In neonates with pulmonary hypertension of the newborn (PPHN) or severe hypoxic respiratory failure, iNO improves oxygenation and decreases the need for ECMO [41, 42]. At an oxygenation index of 20 or higher and/or a pre- and postductal saturation difference of $10 \%$ or more, iNO may be given for at least $1 \mathrm{~h}$. A consistent dose-dependent effect of iNO has not yet been shown [43]. As in one study more infants treated with NO needed ECMO [43], we recommend stopping iNO therapy if no effect is seen after its initiation.

If there is no or an insufficient response to iNO, intravenous prostacyclin, intravenous phosphodiesterase type 5 inhibitor (sildenafil) or medication involving the endothelin pathway should be considered. These agents have been used successfully in treating PPHN in neonates with and without $\mathrm{CDH}[44,45]$. The effects of treatment may be best addressed by repeated cardiac evaluation [46]. This can lead to insufficient filling of the left ventricle and thereby to poor systemic perfusion. Reopening of the ductus arteriosus with prostaglandin E1 may protect the right ventricle from excessive overload due to increased afterload [47]. Phosphodiesterase-3 inhibitor (Milrinone) was investigated in only $6 \mathrm{CDH}$ patients by Patel et al. [48]. Right ventricular function and oxygenation index significantly improved. Sildenafil has been used in the treatment of pulmonary hypertension in infants with $\mathrm{CDH}$. Intravenous sildenafil has recently become available, but its use has not yet been FDA approved.

\section{Recommendations}

- Perform echocardiography within the first $24 \mathrm{~h}$ after birth to rule out structural cardiac anomalies (grade of recommendation $=\mathrm{D}$ ).

- Blood pressure support should be given to maintain arterial blood pressure levels at normal levels for gestation (grade of recommendation $=\mathrm{D}$ ).

- iNO administration for at least $1 \mathrm{~h}$ in a dose of 10-20 ppm should be considered if there is evidence of extrapulmonary right-to-left shunting and the oxygenation index is above 20 and/or the saturation difference is more than $10 \%$ (grade of recommendation = D).

- In nonresponders iNO should be stopped. iNO responders are defined as follows: a decline of $10-20 \%$ in the pre-postductal saturation difference, or an increase of $10-20 \%$ of $\mathrm{PaO}_{2}$, or improvement in hemodynamic parameters meaning a $10 \%$ increase in mean blood pressure, or a decrease in lactate levels (grade of recommendation = D).

- Intravenous sildenafil should be considered in $\mathrm{CDH}$ patients with severe pulmonary hypertension (grade of recommendation $=\mathrm{D}$ ).

- In case of suprasystemic pulmonary artery pressure and right-to-left shunting through the foramen ovale, intravenous prostaglandin E1 should be considered (grade of recommendation $=\mathrm{D})$.

\section{Extracorporeal Membrane Oxygenation}

The benefit of ECMO in the treatment of infants with $\mathrm{CDH}$ remains unclear. The ELSO registry showed a survival rate of $51 \%$ of patients with $\mathrm{CDH}$ who required ECMO [49]. The use of ECMO has decreased in recent years [50]; it is more used for preoperative stabilization, and the preferred method (venoarterial vs. venovenous) is still being debated. The VICI-trial showed no difference in survival between patients born in ECMO centers and patients born in non-ECMO centers [3].

Recommendations

- Criteria for ECMO (grade of recommendation = D):

- Inability to maintain preductal saturations $>85 \%$ or postductal saturations $>70 \%$.

- Increased $\mathrm{PaCO}_{2}$ and respiratory acidosis with $\mathrm{pH}$ $<7.15$ despite optimization of ventilator management.

- Peak inspiratory pressure $>28 \mathrm{~cm} \mathrm{H}_{2} \mathrm{O}$ or mean airway pressure $>17 \mathrm{~cm} \mathrm{H}_{2} \mathrm{O}$ is required to achieve saturation $>85 \%$.

- Inadequate oxygen delivery with metabolic acidosis as measured by elevated lactate $\geq 5 \mathrm{mmol} / \mathrm{l}$ and $\mathrm{pH}<7.15$.

- Systemic hypotension, resistant to fluid and inotropic therapy, resulting in urine output $<0.5 \mathrm{ml} / \mathrm{kg} / \mathrm{h}$ for at least $12-24 \mathrm{~h}$.

- Oxygenation index $\geq 40$ present for at least $3 \mathrm{~h}$.

\section{Surgical Repair}

Surgery should be performed electively. The effect of hospital volume on mortality is unclear. While a large study (2,203 infants) concluded that hospitals with a high volume of $\mathrm{CDH}$ repair have lower in-hospital mortality [51], a more recent study in 3,738 infants showed no difference in mortality between lower and higher surgical volume centers [52]. Controversies about the exact timing of the surgical repair in patients on ECMO remain [53]. A recent study from Partridge et al. [54] showed improved outcomes with surgical repair after ECMO, i.e. a higher likelihood of sur- 
vival, less surgical bleeding and shorter duration of ECMO. A relative small study $(n=46)$ from Fallon et al. [55] found that repair within the first $72 \mathrm{~h}$ of ECMO correlated with a shorter duration of ECMO, less circuit complications and a trend towards improved survival.

The routine use of a chest tube postoperatively to drain the effusion filling the pleural cavity has been abandoned. This does not preclude its use in individual cases to drain an effusion that is symptomatic, for example due to chylothorax existing before surgery.

The optimal surgical technique also remains under debate. Minimal access surgery is gaining ground on the open approach (thoracotomy or laparotomy) [56]. Minimal access surgery has esthetic advantages and may be performed in patients with a left-sided defect and liver down, but carries a significantly higher risk of recurrence $[56,57]$. There is also concern about absorption of $\mathrm{CO}_{2}$ used for insufflation in minimal access surgery [58], and $\mathrm{CO}_{2}$ insufflation pressures should therefore be minimized. A meta-analysis from Lansdale et al. [59] showed that thoracoscopic repair had greater recurrence rates and operative times but similar survival and patch usage compared with open surgery. Recently, Costerus et al. [60] concluded that thoracoscopic primary closure seems a safe and effective procedure, but efficacy of thoracoscopic patch repair has not been established. To allow for better comparison of patient groups between studies it is recommended to record the diaphragmatic defect size in all surgeries [37].

\section{Recommendations}

- Surgical repair of the diaphragmatic defect should be performed after clinical stabilization, defined as follows (grade of recommendation $=\mathrm{D}$ ):

- Mean arterial blood pressure normal for gestation.

- Preductal saturation levels of $85-95 \%$ on $\mathrm{FiO}_{2}$ below $50 \%$.

- Lactate below $3 \mathrm{mmol} / \mathrm{l}$.

- Urine output more than $1 \mathrm{ml} / \mathrm{kg} / \mathrm{h}$.

- No routine chest tube placement postoperatively (grade of recommendation $=\mathrm{D}$ ).

- Repair can be performed while the patient is on ECMO (grade of recommendation $=\mathrm{D})$.

\section{Fluid Management, Parenteral Feeding, Entering Enteral Feeding and Gastroesophageal Reflux}

Restrictive fluid management in the first $24 \mathrm{~h}$ after birth consists of $40 \mathrm{ml} / \mathrm{kg} /$ day of fluids including medication, with additional saline volume top-up for intravascular filling in the case of inadequate tissue perfusion or hypotension. Parenteral nutrition only is allowed until surgical repair and until postoperative enteral feeding has been achieved. Gastroesophageal reflux may be treated both by antireflux medication and by surgical intervention [61]. Maier et al. [62] did not show evidence for profit beyond the first year of life after prophylactic Thal procedure at primary $\mathrm{CDH}$ repair. Diuretics should be given in the case of persisting positive fluid balance without hypovolemia, aiming for diuresis of $>1 \mathrm{ml} / \mathrm{kg} / \mathrm{h}$ [63] .

\section{Recommendations}

- $40 \mathrm{ml} / \mathrm{kg} /$ day saline including medication for the first $24 \mathrm{~h}$ after birth; increase intake thereafter (grade of recommendation $=\mathrm{D}$ ).

- Diuretics should be considered in the case of persisting positive fluid balance; aim for a diuresis $>1 \mathrm{ml} / \mathrm{kg} / \mathrm{h}$ (grade of recommendation $=\mathrm{D}$ ).

- Preventive antireflux therapy should be started in combination with enteral feeding (grade of recommendation $=\mathrm{D})$.

- Preoperatively, patients should only receive parenteral nutrition (grade of recommendation $=\mathrm{D}$ ).

\section{Conclusion}

The European task force for CDH (CDH EURO Consortium) has agreed on an updated protocol for standardized postnatal treatment guidelines. Although it is eminence-based medicine and many recommendations are level D, we think that a consensus of many specialized centers on the use of a standardized treatment protocol will contribute to making more valid comparisons of patient data in ongoing and future multicenter prospective clinical studies.

\section{Appendix}

Members of the CDH EURO Consortium Group:

Austria, Graz, Medical University Graz: B. Urlesberger; Belgium, Leuven, University Hospital KU Leuven: K. Allegaert, A. Debeer, J. Deprest; Canada, Manitoba, University of Manitoba: R. Keijzer; France, Paris, Hôpital Antoine-Béclère: A. Benachi; France, Lille, Hôpital Jeanne de Flandre: L. Storme; France, Paris, South Paris University Hospitals: P. Tissieres; Germany, Bonn, Universitätsklinikum Bonn: F. Kipfmueller; Germany, Mannheim, Universitätsklinikum Mannheim: T. Schaible, L. Wessel; Ireland, Dublin, Our Lady's Children's Hospital: C. Breatnach; Scotland, Glasgow, Royal Hospital for Sick Children: N. Patel; Italy, Milan, Fondazione IRCCS Cà Granda, Ospedale maggiore policlinico: E. Leva, F. Ciralli; Italy, Rome, Bambino Gesu Children's Hospital: P.
Snoek et al. 
Bagolan, I. Capolupo, A. Dotta, F. Morini, A. di Pede; Norway, Oslo, Oslo University Hospital: R. Emblem, K. Ertesvag; Poland, Warsaw, Centrum Zdrowia Dziecka: M. Migdal, A. Piotrowski; Sweden, Stockholm, Karolinska Univeristy: B. Frenckner, C. Mesas; Spain, Madrid, Hospital University La Paz: D. Elorza, L. Martinez; The Netherlands, Nijmegen, Radboud University Medical Centre: A. van Heijst, H. Scharbatke; The Netherlands, Rotterdam, Erasmus MC-Sophia Children's Hospital University Medical Center Rotterdam: T. Cohen-Overbeek, A.J. Eggink, U.S. Kraemer, I.K.M. Reiss, K.G. Snoek, D. Tibboel, R.M.H. Wijnen; UK, Lon- don, University College London Hospitals: J. Deprest; United Kingdom, London, UCL Institute of Child Health and Great Ormond Street Hospital for Children: P. De Coppi, S. Eaton; UK, London, King's College: M. Davenport, A. Greenough.

\section{Acknowledgment}

We thank Ko Hagoort for editing.

\section{References}

1 Reiss I, Schaible T, van den Hout L, Capolupo I, Allegaert K, van Heijst A, Gorett Silva M, Greenough A, Tibboel D; CDH EURO Consortium: Standardized postnatal management of infants with congenital diaphragmatic hernia in Europe: The CDH EURO Consortium consensus. Neonatology 2010;98:354-364.

2 Harbour R, Miller J: A new system for grading recommendations in evidence-based guidelines. BMJ 2001;323:334-336.

3 Snoek KG, Capolupo I, van Rosmalen J, Hout LJ, Vijfhuize S, Greenough A, Wijnen RM, Tibboel D, Reiss IK; CDH EURO Consortium: Conventional mechanical ventilation versus high-frequency oscillatory ventilation for congenital diaphragmatic hernia: a randomized clinical trial (the VICI-trial). Ann Surg 2015, Epub ahead of print.

4 Gentili A, Pasini L, Iannella E, Landuzzi V, Lima M, Bacchi Reggiani ML, Baroncini S: Predictive outcome indexes in neonatal congenital diaphragmatic hernia. J Matern Fetal Neonatal Med 2015;28:1602-1607.

5 Jani JC, Benachi A, Nicolaides KH, Allegaert K, Gratacos E, Mazkereth R, Matis J, Tibboel D, Van Heijst A, Storme L, Rousseau V, Greenough A, Deprest JA; Antenatal CDH Registry Group: Prenatal prediction of neonatal morbidity in survivors with congenital diaphragmatic hernia: a multicenter study. Ultrasound Obstet Gynecol 2009;33:64-69.

6 Beaumier CK, Beres AL, Puligandla PS, Skarsgard ED; Canadian Pediatric Surgery Network: Clinical characteristics and outcomes of patients with right congenital diaphragmatic hernia: a population-based study. J Pediatr Surg 2015;50:731-733.

7 Harting MT, Lally KP: The congenital diaphragmatic hernia study group registry update. Semin Fetal Neonatal Med 2014;19:370-375.

8 Weidner M, Hagelstein C, Debus A, Walleyo A, Weiss C, Schoenberg SO, Schaible T, Busing KA, Kehl S, Neff KW: MRI-based ratio of fetal lung volume to fetal body volume as a new prognostic marker in congenital diaphragmatic hernia. AJR Am J Roentgenol 2014;202:1330-1336.

9 Nasr A, Langer JC; Canadian Pediatric Surgery Network: Influence of location of delivery on outcome in neonates with congenital diaphragmatic hernia. J Pediatr Surg 2011;46: 814-816.

10 Grushka JR, Laberge JM, Puligandla P, Skarsgard ED; Canadian Pediatric Surgery Network: Effect of hospital case volume on outcome in congenital diaphragmatic hernia: the experience of the Canadian Pediatric Surgery Network. J Pediatr Surg 2009;44:873-876.

11 Grivell RM, Andersen C, Dodd JM: Prenatal interventions for congenital diaphragmatic hernia for improving outcomes. Cochrane Database Syst Rev 2015;11:CD008925.

12 Deprest J, Brady P, Nicolaides K, Benachi A, Berg C, Vermeesch J, Gardener G, Gratacos E: Prenatal management of the fetus with isolated congenital diaphragmatic hernia in the era of the total trial. Semin Fetal Neonatal Med 2014;19:338-348.

13 Jani JC, Nicolaides KH, Gratacos E, Valencia CM, Done E, Martinez JM, Gucciardo L, Cruz R, Deprest JA: Severe diaphragmatic hernia treated by fetal endoscopic tracheal occlusion. Ultrasound Obstet Gynecol 2009;34:304-310.

14 Hutcheon JA, Butler B, Lisonkova S, Marquette GP, Mayer C, Skoll A, Joseph KS: Timing of delivery for pregnancies with congenital diaphragmatic hernia. BJOG 2010;117: 1658-1662.

15 Odibo AO, Najaf T, Vachharajani A, Warner B, Mathur A, Warner BW: Predictors of the need for extracorporeal membrane oxygenation and survival in congenital diaphragmatic hernia: a center's 10-year experience. Prenat Diagn 2010;30:518-521.

16 Safavi A, Lin Y, Skarsgard ED; Canadian Pediatric Surgery Network: Perinatal management of congenital diaphragmatic hernia: when and how should babies be delivered? Results from the Canadian Pediatric Surgery Network. J Pediatr Surg 2010;45:2334-2339.

17 Perlman JM, Wyllie J, Kattwinkel J, Atkins DL, Chameides L, Goldsmith JP, Guinsburg R, Hazinski MF, Morley C, Richmond S, Simon WM, Singhal N, Szyld E, Tamura M, Velaphi S; Neonatal Resuscitation Chapter Collaborators: Part 11: neonatal resuscitation: 2010 international consensus on cardiopulmonary resuscitation and emergency cardiovascular care science with treatment recommendations. Circulation 2010;122:S516-S538.
18 Dawson JA, Kamlin CO, Vento M, Wong C, Cole TJ, Donath SM, Davis PG, Morley CJ: Defining the reference range for oxygen saturation for infants after birth. Pediatrics 2010; 125:e1340-e1347.

19 Davis PG, Tan A, O'Donnell CP, Schulze A: Resuscitation of newborn infants with $100 \%$ oxygen or air: a systematic review and metaanalysis. Lancet 2004;364:1329-1333.

20 Rabi Y, Rabi D, Yee W: Room air resuscitation of the depressed newborn: a systematic review and meta-analysis. Resuscitation 2007;72: 353-363.

21 Carbajal R, Eble B, Anand KJ: Premedication for tracheal intubation in neonates: confusion or controversy? Semin Perinatol 2007;31: 309-317.

22 Caldwell CD, Watterberg KL: Effect of premedication regimen on infant pain and stress response to endotracheal intubation. J Perinatol 2015;35:415-418.

23 Le CN, Garey DM, Leone TA, Goodmar JK, Rich W, Finer NN: Impact of premedication on neonatal intubations by pediatric and neonatal trainees. J Perinatol 2014;34:458-460.

24 Murthy V, D'Costa W, Nicolaides K, Davenport M, Fox G, Milner AD, Campbell M, Greenough A: Neuromuscular blockade and lung function during resuscitation of infants with congenital diaphragmatic hernia. Neonatology 2013;103:112-117.

25 Houfflin Debarge V, Sicot B, Jaillard S, Gueorgiva I, Delelis A, Deruelle P, Ducloy AS, Storme $\mathrm{L}$ : The mechanisms of pain-induced pulmonary vasoconstriction: an experimental study in fetal lambs. Anesth Analg 2007;104:799-806.

26 Kamath BD, Fashaw L, Kinsella JP: Adrenal insufficiency in newborns with congenital diaphragmatic hernia. J Pediatr 2010;156:495497.e491.

27 Boucherat O, Benachi A, Chailley-Heu B, Franco-Montoya ML, Elie C, Martinovic J, Bourbon JR: Surfactant maturation is not delayed in human fetuses with diaphragmatic hernia. PLoS Med 2007;4:e237.

28 Guidry CA, Hranjec T, Rodgers BM, Kane B, McGahren ED: Permissive hypercapnia in the management of congenital diaphragmatic hernia: our institutional experience. J Am Coll Surg 2012;214:640-645; discussion 646-647. 
29 Lupo E, Castoldi F, Maestri L, Rustico M, Dani C, Lista G: Outcome of congenital diaphragmatic hernia: analysis of implicated factors. Minerva Pediatr 2013;65:279-285.

30 van den Hout L, Tibboel D, Vijfhuize S, te Beest H, Hop W, Reiss I; CDH EURO Consortium: The VICI-trial: high frequency oscillation versus conventional mechanical ventilation in newborns with congenital diaphragmatic hernia: an international multicentre randomized controlled trial. BMC Pediatr 2011;11:98.

31 Bellu R, de Waal KA, Zanini R: Opioids for neonates receiving mechanical ventilation. Cochrane Database Syst Rev 2008;1:CD004212.

32 Aranda JV, Carlo W, Hummel P, Thomas R, Lehr VT, Anand KJ: Analgesia and sedation during mechanical ventilation in neonates. Clin Ther 2005;27:877-899.

33 Giliberti P, Mondi V, Conforti A, Lombardi MH, Sgro S, Bozza P, Picardo S, Dotta A, Bagolan P: Near infrared spectroscopy in newborns with surgical disease. J Matern Fetal Neonatal Med 2011;24(suppl 1):56-58.

34 Ista E, van Dijk M, Tibboel D, de Hoog M: Assessment of sedation levels in pediatric intensive care patients can be improved by using the comfort 'behavior' scale. Pediatr Crit Care Med 2005;6:58-63.

35 Bonafide CP, Brady PW, Keren R, Conway PH, Marsolo K, Daymont C: Development of heart and respiratory rate percentile curves for hospitalized children. Pediatrics 2013; 131:e1150-e1157.

36 Brierley J, Carcillo JA, Choong K, Cornell T, Decaen A, Deymann A, et al: Clinical practice parameters for hemodynamic support of pediatric and neonatal septic shock: 2007 update from the American College of Critical Care Medicine. Crit Care Med 2009;37:666-688.

37 Lally KP, Lasky RE, Lally PA, Bagolan P, Davis CF, Frenckner BP, Hirschl RM, Langham MR, Buchmiller TL, Usui N, Tibboel D, Wilson JM; Congenital Diaphragmatic Hernia Study Group: Standardized reporting for congenital diaphragmatic hernia - an international consensus. J Pediatr Surg 2013;48: 2408-2415.

38 Patel N, Mills JF, Cheung MM: Assessment of right ventricular function using tissue Doppler imaging in infants with pulmonary hypertension. Neonatology 2009;96:193-199; discussion 200-192.

39 Moenkemeyer F, Patel N: Right ventricular diastolic function measured by tissue Doppler imaging predicts early outcome in congenital diaphragmatic hernia. Pediatr Crit Care Med 2014;15:49-55.
40 Kent AL, Meskell S, Falk MC, Shadbolt B: Normative blood pressure data in non-ventilated premature neonates from 28-36 weeks gestation. Pediatr Nephrol 2009;24:141-146.

41 Konduri GG, Solimano A, Sokol GM, Singer J, Ehrenkranz RA, Singhal N, Wright LL, Van Meurs K, Stork E, Kirpalani H, Peliowski A; Neonatal Inhaled Nitric Oxide Study Group: A randomized trial of early versus standard inhaled nitric oxide therapy in term and nearterm newborn infants with hypoxic respiratory failure. Pediatrics 2004;113:559-564.

42 Sadiq HF, Mantych G, Benawra RS, Devaskar UP, Hocker JR: Inhaled nitric oxide in the treatment of moderate persistent pulmonary hypertension of the newborn: a randomized controlled, multicenter trial. J Perinatol 2003; 23:98-103.

43 Wood KS, McCaffrey MJ, Donovan JC, Stiles $\mathrm{AD}$, Bose CL: Effect of initial nitric oxide concentration on outcome in infants with persistent pulmonary hypertension of the newborn. Biol Neonate 1999;75:215-224.

44 Uslu S, Kumtepe S, Bulbul A, Comert S, Bolat F, Nuhoglu A: A comparison of magnesium sulphate and sildenafil in the treatment of the newborns with persistent pulmonary hypertension: a randomized controlled trial. J Trop Pediatr 2011;57:245-250.

45 Mohamed WA, Ismail M: A randomized, double-blind, placebo-controlled, prospective study of bosentan for the treatment of persistent pulmonary hypertension of the newborn. J Perinatol 2012;32:608-613.

46 Lusk LA, Wai KC, Moon-Grady AJ, Steurer MA, Keller RL: Persistence of pulmonary hypertension by echocardiography predicts short-term outcomes in congenital diaphragmatic hernia. J Pediatr 2015;166:251-256. e251.

47 Mohseni-Bod H, Bohn D: Pulmonary hypertension in congenital diaphragmatic hernia. Semin Pediatr Surg 2007;16:126-133.

48 Patel N: Use of milrinone to treat cardiac dysfunction in infants with pulmonary hypertension secondary to congenital diaphragmatic hernia: a review of six patients. Neonatology 2012;102:130-136.

49 ELSO Registry: ECLS Registry Report International Summary. 2014. Extracorporeal Life Support Organization, 2014. http://www.elso. org/registry.

50 Paden ML, Conrad SA, Rycus PT, Thiagarajan RR; ELSO Registry: Extracorporeal Life Support Organization Registry Report 2012. ASAIO J 2013;59:202-210.

51 Bucher BT, Guth RM, Saito JM, Najaf T, Warner BW: Impact of hospital volume on in-hospital mortality of infants undergoing repair of congenital diaphragmatic hernia. Ann Surg 2010;252:635-642.
52 Kane JM, Harbert J, Hohmann S, Pillai S, Behal R, Selip D, Johnson T: Case volume and outcomes of congenital diaphragmatic hernia surgery in academic medical centers. Am J Perinatol 2015;32:845-852.

53 Desai AA, Ostlie DJ, Juang D: Optimal timing of congenital diaphragmatic hernia repair in infants on extracorporeal membrane oxygenation. Semin Pediatr Surg 2015;24:17-19.

54 Partridge EA, Peranteau WH, Rintoul NE, Herkert LM, Flake AW, Adzick NS, Hedrick HL: Timing of repair of congenital diaphragmatic hernia in patients supported by extracorporeal membrane oxygenation (ECMO). J Pediatr Surg 2015;50:260-262.

55 Fallon SC, Cass DL, Olutoye OO, Zamora IJ, Lazar DA, Larimer EL, Welty SE, Moise AA, Demny AB, Lee TC: Repair of congenital diaphragmatic hernias on extracorporeal membrane oxygenation (ECMO): does early repair improve patient survival? J Pediatr Surg 2013; 48:1172-1176.

56 Vijfhuize S, Deden AC, Costerus SA, Sloots CE, Wijnen RM: Minimal access surgery for repair of congenital diaphragmatic hernia: is it advantageous? - An open review. Eur J Pediatr Surg 2012;22:364-373.

57 Zani A, Zani-Ruttenstock E, Pierro A: Advances in the surgical approach to congenital diaphragmatic hernia. Semin Fetal Neonatal Med 2014;19:364-369.

58 Pierro A: Hypercapnia and acidosis during the thoracoscopic repair of oesophageal atresia and congenital diaphragmatic hernia. J Pediatr Surg 2015;50:247-249.

59 Lansdale N, Alam S, Losty PD, Jesudason EC: Neonatal endosurgical congenital diaphragmatic hernia repair: a systematic review and meta-analysis. Ann Surg 2010;252:20-26.

60 Costerus S, Zahn K, van de Ven K, Vlot J, Wessel L, Wijnen R: Thoracoscopic versus open repair of $\mathrm{CDH}$ in cardiovascular stable neonates. Surg Endosc 2015, Epub ahead of print.

61 Verbelen T, Lerut T, Coosemans W, De Leyn P, Nafteux P, Van Raemdonck D, Deprest J, Decaluwe H: Antireflux surgery after congenital diaphragmatic hernia repair: a plea for a tailored approach. Eur J Cardiothorac Surg 2013;44:263-267; discussion 268.

62 Maier S, Zahn K, Wessel LM, Schaible T, Brade J, Reinshagen K: Preventive antireflux surgery in neonates with congenital diaphragmatic hernia: a single-blinded prospective study. J Pediatr Surg 2011;46:1510-1515.

63 Pacifici GM: Clinical pharmacology of the loop diuretics furosemide and bumetanide in neonates and infants. Paediatr Drugs 2012;14 233-246. 